\title{
Treatment of suicidal people around the world ${ }^{\dagger}$
}

R. Bruffaerts, K. Demyttenaere, I. Hwang, W.-T. Chiu, N. Sampson, R. C. Kessler, J. Alonso,

G. Borges, G. de Girolamo, R. de Graaf, S. Florescu, O. Gureje, C. Hu, E. G. Karam, N. Kawakami,

S. Kostyuchenko, V. Kovess-Masfety, S. Lee, D. Levinson, H. Matschinger, J. Posada-Villa, R. Sagar,

K. M. Scott, D. J. Stein, T. Tomov, M. C. Viana and M. K. Nock

\section{Background}

Suicide is a leading cause of death worldwide; however, little information is available about the treatment of suicidal people, or about barriers to treatment.

\begin{abstract}
Aims
To examine the receipt of mental health treatment and barriers to care among suicidal people around the world.
\end{abstract}

\section{Method}

Twenty-one nationally representative samples worldwide ( $n=55302$; age 18 years and over) from the World Health Organization's World Mental Health Surveys were interviewed regarding past-year suicidal behaviour and past-year healthcare use. Suicidal respondents who had not used services in the past year were asked why they had not sought care.

\section{Results}

Two-fifths of the suicidal respondents had received treatment (from $17 \%$ in low-income countries to $56 \%$ in high-income countries), mostly from a general medical practitioner (22\%), psychiatrist (15\%) or non-psychiatrist (15\%). Those who had actually attempted suicide were more likely to receive care.
Low perceived need was the most important reason for not seeking help (58\%), followed by attitudinal barriers such as the wish to handle the problem alone (40\%) and structural barriers such as financial concerns (15\%). Only $7 \%$ of respondents endorsed stigma as a reason for not seeking treatment.

\section{Conclusions}

Most people with suicide ideation, plans and attempts receive no treatment. This is a consistent and pervasive finding, especially in low-income countries. Improving the receipt of treatment worldwide will have to take into account culture-specific factors that may influence the process of help-seeking

\section{Declaration of interest}

R.C.K. has been a consultant for GlaxosmithKline, Kaiser Permanente, Pfizer, Sanofi-Aventis, Shire Pharmaceuticals and Wyeth-Ayerst; has served on advisory boards for Eli Lilly \& Co. and Wyeth-Ayerst; and has had research support for his epidemiological studies from Bristol-Myers Squibb, Eli Lilly, GlaxosmithKline, Johnson \& Johnson Pharmaceuticals, Ortho-McNeil Pharmaceuticals, Pfizer and Sanofi-Aventis.
Suicidal behaviour is a persistent and lethal public health problem. ${ }^{1,2}$ Worldwide, suicide is among the leading causes of death. ${ }^{3,4}$ Prevention programmes have been established over the years, ${ }^{5,6}$ several of which have shown some effectiveness in decreasing the risk of suicide. ${ }^{7}$ Only a few psychological treatments have demonstrated an ability to decrease the risk of suicidal behaviour. ${ }^{8,9}$ Unfortunately, available data suggest that many people who are suicidal do not seek treatment. ${ }^{10}$ Although there is widespread agreement on the importance of suicide prevention efforts, basic information about the treatment of people who are suicidal is not available. For instance, there are no cross-national data available that document the proportion of suicidal people who actually receive treatment or the reasons why some of them do not seek treatment. Obtaining this information is vital for the identification of unmet needs and is an important first step for future prevention efforts.

The World Health Organization (WHO) World Mental Health surveys were designed, among other objectives, to address each of these shortcomings. These general population-based surveys use structured psychiatric interviews, validated for use worldwide, to measure the presence of mental disorders and suicidal behaviour, as well as treatment use and barriers to care. The current study builds on earlier World Mental Health studies reporting on the cross-national treatment of mental disorders, ${ }^{11}$ and on the 12 -month prevalence of suicidal behaviour, ${ }^{12}$ and provides comprehensive cross-national data on the treatment of suicidal people. The specific aims of the study were to investigate:

†See editorial, pp. 8-10, this issue. (a) the proportion of suicidal respondents who had received some form of treatment;

(b) multivariate predictors of treatment use;

(c) barriers to receiving treatment;

(d) multivariate predictors of barriers to treatment;

(e) variations of treatment use across low-, middle- and highincome countries worldwide.

\section{Method}

The World Mental Health surveys were carried out in 21 countries in six continents, including Africa (Nigeria, South Africa), Asia (India, Israel, Japan, Lebanon, China - Beijing, Shanghai and Shenzhen), Australasia (New Zealand), Europe (Belgium, Bulgaria, France, Germany, Italy, The Netherlands, Romania, Spain, Ukraine) and North and South America (Brazil, Colombia, Mexico, USA). Respondents were selected using a stratified multistage clustered-area probability sampling strategy, apart from Japan where an unclustered two-stage probability sampling method was used. The total sample size was 109381 with individual country sample sizes ranging from 2357 in Romania to 12790 in New Zealand. The weighted average response rate across all countries was $72.1 \%$. Using World Bank criteria, ${ }^{13}$ countries were classified as low-income (Colombia, India, Nigeria, China and Ukraine), middle-income (Brazil, Bulgaria, Lebanon, Mexico, Romania and South Africa) and high-income (all other survey countries) (see online Table DS1). Surveys were conducted face-to-face by trained lay interviewers. Informed consent was 
obtained before beginning interviews. Internal subsampling was used to reduce respondent burden by dividing the interview into two parts. Part 1 (given to all respondents) included sociodemographic variables, the core diagnostic assessment of mental disorders and suicidal behaviours. All Part 1 respondents who met criteria for any lifetime mental disorder, and a probability sample of other respondents, were administered Part 2 of the interview, which included additional information on access to care. Part 2 respondents' data were weighted by the inverse of their probability of selection for Part 2 of the interview to adjust for differential sampling. Analyses in this study were based on the weighted Part 2 subsample $(n=55302)$. Additional weights were used to adjust for differential probabilities of selection within households, to adjust for non-response, and to match the samples to population sociodemographic distributions. Further details of the survey design are reported elsewhere. ${ }^{14-16}$

The WHO translation-back translation protocol was used to translate instruments and training materials. Translations were made by bilingual individuals with consultation to expert panels (with psychiatrists, psychologists and mental health researchers). The following steps were performed: translation from the original English version into the target language by two independent translators; review of these translations by a bilingual group and production of a revised version; translation of the revised version back into English by two different translators; and review of the back translations and production of the final version by the bilingual group. This protocol was followed in order to obtain instruments with acceptable cross-cultural validity for use worldwide. $^{17}$

\section{Classification of suicidality}

Suicidality was assessed using the Composite International Diagnostic Interview (CIDI) 3.0 suicidality module. ${ }^{18}$ Based on their responses to questions about the experience of suicide ideation, plans and attempts (both planned and unplanned) in the preceding 12 months, respondents who endorsed a history of any suicidal thought or behaviour were classified into one of four groups of increasing severity: suicide ideation only, suicide plan, unplanned suicide attempt and planned suicide attempt.

\section{Treatment and barriers to care}

Treatment use was assessed by the CIDI-3.0 treatment module regarding past year receipt of treatment from any type of professional, either as an out-patient or in-patient, for problems with emotion regulation, anxiety, psychological distress or use of alcohol or drugs. ${ }^{11,18}$ Included were mental health professionals (e.g. psychiatrists, psychologists), general medical professionals (e.g. general practitioners, occupational therapists) and other non-healthcare professionals (e.g. religious counsellors, traditional healers, complementary or alternative medicine practitioners). Examples of these types of providers were presented in a booklet given to respondents as a visual recall aid. Respondents who reported no use of health services were asked whether there was a time in the past year when they had felt that they might have needed to see a professional for problems with their emotion regulation, anxiety or psychological distress. Those who answered affirmatively were asked to indicate which of the following reasons for not seeing a professional applied to them: low perceived need, structural barriers (i.e. lack of financial means, available treatments, personnel or transportation, or the presence of other inconveniences) and attitudinal barriers (i.e. the presence of stigma, low perceived efficacy of treatments or the desire to handle the problem on their own). Participants who responded that they did not need treatment in the past 12 months (i.e. they endorsed the statement, 'The problem went away by itself, and I did not really need help' as a reason for not seeking treatment) were not asked about structural or attitudinal barriers and were coded as respondents with low perceived need (see Appendix for specific items).

\section{Statistical analysis}

Descriptive statistics were used to estimate the prevalence of past-year treatment use and barriers to care among suicidal respondents. Multivariate logistic regression models examined variations in treatment use associated with sociodemographic variables, suicidality severity, treatment history and lifetime history of respondents' mental disorders (mood, anxiety, substance use or impulse control disorders) as assessed by the CIDI version 3.0. Four main effect models were run, one for each of the three healthcare sectors (any mental health treatment, general medical treatment and any non-healthcare) and one for the entire sample. A similar approach was used to study barriers to treatment. In the logistic regression models, coefficients and standard errors were exponentiated for ease of interpretation and are reported as odds ratios with 95\% confidence intervals. Multivariate predictors for either seeking treatment or barriers to treatment were adjusted for the possible influence of national differences, sociodemographic characteristics, suicidality severity, time (in years) since onset of suicidal ideation, treatment history and presence of DSM-IV lifetime mental disorders. Standard errors were estimated with the Taylor series method, ${ }^{19}$ using SUDAAN software (Software for Survey Data Analysis, version 8.1 on UNIX-Solaris/SUN operating system; www.rti.org/ SUDAAN), to adjust for weighting and clustering. ${ }^{20}$ Multivariate significance was evaluated with Wald chi-squared tests based on design-corrected coefficient variance-covariance matrices. Statistical significance was evaluated using two-sided design-based tests and the $P<0.05$ level of significance.

\section{Results}

\section{Treatment of suicidal people}

Thirty-nine per cent of people who had engaged in suicidal behaviour in the past year had received some form of treatment for emotional difficulties in the past year (Table 1). Those with higher severity of suicidality accessed care at higher rates: 34$42 \%$ of those with suicidal thoughts (i.e. suicide ideation or plan) received care compared with $49-55 \%$ of those who made a suicide attempt. The type of care received most often by suicidal respondents was mental healthcare $(23 \%$ of all suicidal respondents) followed by general medical care (22\%) and nonhealthcare services $(11 \%)$. Receiving some form of treatment was predicted by higher education and income, married status, a past history of treatment and the presence of a mood or anxiety disorder (Table DS2). In addition, greater severity of suicidal behaviour and shorter time since first onset of suicidal ideation were associated with higher odds of receiving treatment. None of these clinical characteristics (suicidality severity, time since onset of the suicide ideation or lifetime mental disorders) or service use characteristics (history of treatment) was associated with higher odds of receiving specific types of treatment (Table DS2). In contrast, those with higher education, higher income and those who were never married had significantly higher odds of receiving mental health treatment; whereas those who were older, had lower education levels and were married had significantly higher odds of receiving general health treatment.

An analysis of differences in the receipt of care among high-, middle- and low-income countries (see Table DS3a-d for data reported separately for each country) revealed that the treatment 


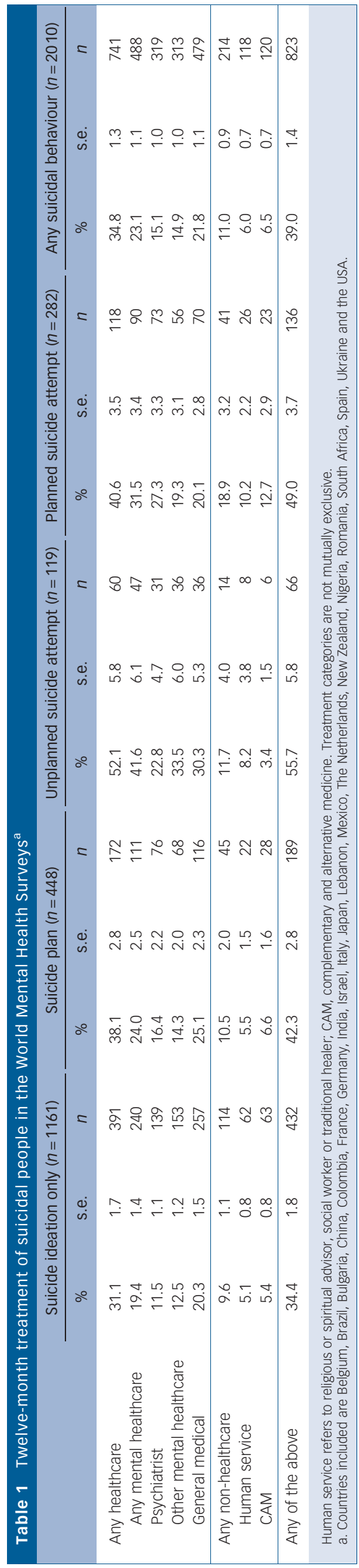

of suicidal behaviour was most prevalent in high-income countries (56\% of those experiencing any suicidal outcome received some form of treatment in the past 12 months) and less prevalent in middle-income $(28 \%)$ and low-income (17\%) countries for each of the suicidal outcomes examined (see Table DS4a-c for more detail).

\section{Barriers to treatment}

Among those who had engaged in suicidal behaviour in the past year but had not received treatment, low perceived need was consistently the most common barrier reported $(58 \%$ of respondents with any suicidal outcome). This was the highest barrier endorsed among respondents with ideation (58\%) and plan $(63 \%)$, as well as those with planned (57\%) and unplanned (40\%) suicide attempts. The next most commonly reported barriers were those related to attitudes about seeking treatment. Of those who were suicidal in the past year but did not receive treatment, $27 \%$ said that they wanted to handle the problem on their own, $12 \%$ believed the problem would get better without treatment, $9 \%$ said the problem was not that severe, $8 \%$ believed that treatment would not be effective and only $7 \%$ reported stigma as the reason for not seeking treatment. The least-often endorsed barriers were structural barriers, which included limited finances $(12 \%)$, lack of availability of treatment $(11 \%)$, problems with transportation $(4 \%)$ and the inconvenience of attending treatment (4\%) (Table 2). Respondents with a history of receiving prior treatment were less likely to have a low perceived need for treatment but more likely to report the experience of structural barriers to treatment (Table DS5). In addition, greater respondent age was associated with the experience of fewer structural barriers. No other clinical or service use characteristics predicted the type of barriers to treatment experienced. Cross-national comparisons of the data revealed that low perceived need for treatment was the most often endorsed reason for not seeking treatment in low-income $(67 \%)$ and middle-income $(62 \%)$ countries. In high-income countries low perceived need for treatment $(45 \%)$ was surpassed by attitudinal barriers (54\%) as the primary reason for not seeking care for suicidal thoughts and behaviours (Table DS6a-c).

\section{Discussion}

This cross-national, population-based survey revealed that most people with suicidal thoughts, plans or attempts do not receive mental health treatment in any form. The rate of treatment was low across each of the 21 countries examined, but was especially low in middle- and low-income countries. Receipt of care was higher among those with more severe suicidality and among those with mood or anxiety disorders. Among suicidal respondents who did not receive any care, the most frequently endorsed reason for failure to seek treatment was low perceived need, followed by other attitudinal and structural barriers.

\section{Limitations}

Our results should be interpreted in the light of several important limitations. First, our study had a moderate response rate (73\%). Non-responders in population surveys are likely to have higher rates of mental disorders than respondents. ${ }^{21}$ Second, respondents who did not speak the primary language of the country sufficiently, those resident in institutions and those without a fixed address were not included in this study. It may be that such people are more likely to be suicidal. Moreover, against the background that suicide risk is elevated among in-patients and specific respondent groups (such as those with psychotic disorder or borderline personality disorder), we might assume that the 


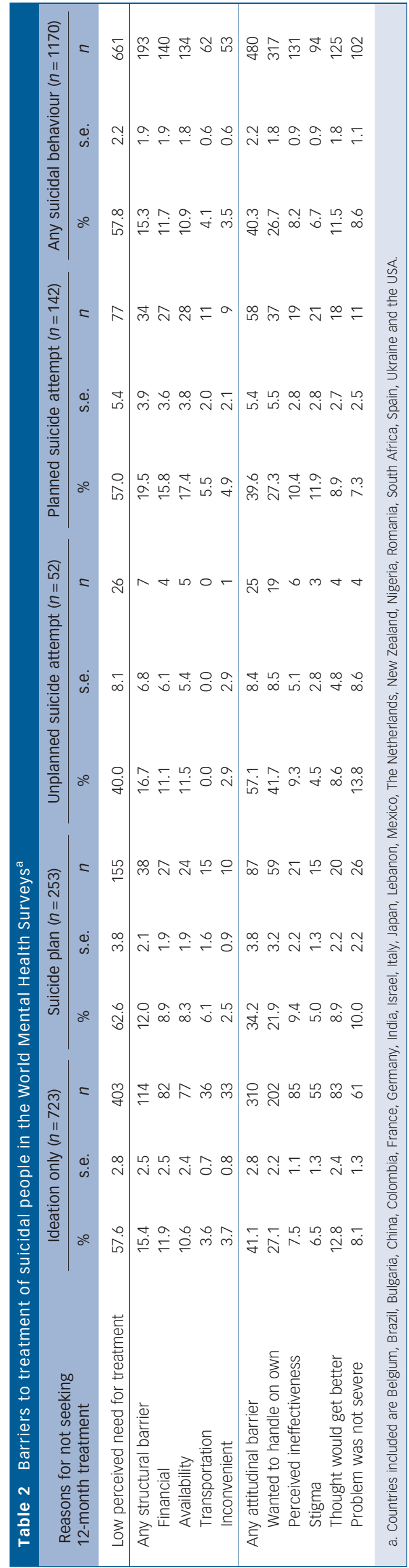

prevalence of suicidal behaviour is higher among psychiatric in-patients than among people living in the community. ${ }^{22}$ Third, the CIDI 3.0 treatment module asks for treatment for emotional or substance misuse problems, not for suicidality specifically, and hence not as a specific behaviour to seek care for. Although we did control for national differences, suicidal behaviour may not always be considered as an emotional or psychological problem, and hence may not be considered a reason to seek help in mental healthcare. Moreover, the information on treatment access did not include information about the adequacy or effectiveness of the treatment received. Indeed, despite some evidence that treatments for mental disorders are also helpful in reducing suicidality, ${ }^{23,24}$ we cannot estimate to what extent treatments obtained in this study for mental disorders were adequate for treating suicidal behaviours. Further research should therefore focus in more detail on received treatment for both mental disorders and suicidal behaviour and criteria defining treatment adequacy/effectiveness. Fourth, because we used a 12-month time frame, we were unable to examine delays in the help-seeking process in the current study. Fifth, responses to the survey may have been biased by the use of retrospective selfreport. Previous studies have shown that the validity of the assessment of service use could be biased dependent upon recall time periods, ${ }^{25}$ or frequency of service use, all leading to a modest underestimation of more recent service use. ${ }^{26}$ Sixth, respondents who did not feel a need for treatment were not asked about structural or attitudinal barriers, possibly leading to an underestimate of stigma. Moreover, we treated stigma as an independent reason for not seeking help, whereas it might be a function of attitudinal or structural barriers.

\section{Unmet need worldwide}

Notwithstanding these limitations, our study indicates that there is a high level of unmet need for treatment of suicidal behaviour worldwide. This unmet need is more dramatic in low- and middle-income countries, where less than one in four suicidal people receives any treatment in a given year. These findings suggest that those who are suicidal are more likely than people with mental disorders to receive treatment; 12-month treatment rates for mental disorders vary significantly worldwide but are all within the $1-15 \%$ range. ${ }^{27}$ Studies have documented that effective treatments are available for suicidal behaviours, in full and partial in-patient ${ }^{24}$ and out-patient ${ }^{8,9}$ settings, as well as in specialised psychiatric emergency programmes, ${ }^{28}$ and so the low rate of treatment revealed in this study is particularly concerning. Furthermore, it is unlikely that most of those who reported receiving treatment in the current study actually received these effective interventions, given that only $23 \%$ of respondents received care from a mental health specialist. Instead, large percentages received treatment in the general medical field (22\%) or non-healthcare settings $(11 \%)$ where evidence-based treatments for suicidal behaviour are unlikely to be available. Despite the large international differences in the structure and organisation of healthcare systems, our findings suggest that these primary care and non-healthcare settings may serve as important entry points into treatment for people engaging in suicidal behaviour. This suggests that general practitioners and other non-mental health providers may serve as gatekeepers for suicidal patients worldwide, ${ }^{29}$ guiding them towards evidence-based treatment in secondary care.

\section{Seeking treatment for suicidality}

The predictors of treatment in the current study are in line with those reported in previous work, with higher education and 
income and greater clinical severity serving as core predictors. ${ }^{10,11}$ However, greater severity of suicidal behaviour was unrelated to the use of the mental healthcare over the use of other treatment. This suggests that although those who make actual suicide attempts are more likely to be treated than those who only think about suicide, they are not more likely to be referred for care from a mental health specialist.

The help-seeking process of suicidal people is complex. Once people have decided to seek treatment, they seem to wait and see whether the problem independently subsides and whether they can rid themselves of the behaviour. ${ }^{30}$ Attitudinal factors may be especially likely among people with suicidal thoughts and behaviours. Such thoughts and behaviours typically are transient in nature, coming and going repeatedly over time. As a result, those experiencing a suicidal crisis may simply try to 'ride it out' until the crisis abates. In addition, those experiencing suicidal thoughts and behaviours typically feel pessimistic and hopeless and so may not have positive expectations that treatment will help them. ${ }^{31}$ The fact that four in ten respondents report attitudinal barriers (e.g. trying to solve the problem on their own) is a crucial finding because these attitudes may be implicated in delaying access to treatment and thus could result in progression of the problem. Attitudinal barriers also may place considerable limits on implementation of evidence-based mental health treatment and prevention programmes. ${ }^{31}$ One way to address these issues is to initiate public awareness programmes about suicide and its appropriate available treatments, as well as the value of educational programmes in suicide prevention, ${ }^{31}$ because time or financial restraints may prevent an overall increase of treatment resources. Indeed, there is extensive literature available demonstrating the relation between insight in emotional problems and acceptance of and compliance with treatment, ${ }^{32}$ as well as between educational programmes and suicide prevention, ${ }^{7}$ and so these represent important possible directions for future work. Discussing the help-seeking process for suicidality around the world, and accordingly deriving implications for the field, becomes even more complicated and difficult because of the cultural and contextual meaning of suicidality. Research has demonstrated the impact of specific cultural attitudes towards suicide rates and help-seeking behaviours. ${ }^{33}$ This suggests that barriers to treatment may not be tackled easily, since barriers may reflect deeply rooted cultural ethics that influence different stages of the help-seeking process. ${ }^{34}$

The idea is widely accepted that both stigma and financial barriers interfere considerably with mental health treatment. ${ }^{35-38}$ Our findings challenge this conventional wisdom and show that across income categories, stigma and financial barriers were reported by a minority of suicidal people (less than a fifth of all conditions studied). This suggests that stigma and financial barriers may not be as important as previously suggested and that prevention efforts may be most effective by targeting other attitudinal barriers. However, as this is the first study that has addressed this question, future research may focus on possible interactions between different kinds of barriers. Further research may also focus on the cultural diversity of the interplay between cultural ethics and barriers to treatment. For instance, one area that might be a focus of further study is the effect of family and/or community reactions after a suicide attempt on the process of seeking help. ${ }^{34}$

\section{Implications}

In an era where great emphasis lies on the prevention of suicide worldwide, this first cross-national, population-based study of the patterns of treatment for suicidal behaviours holds some important implications. Clinicians, policy-makers and healthcare planners should be aware of the significance of the degree of unmet need and the broad range of barriers that prevent suicidal people from seeking treatment, and specific effects of cultural differences on the help-seeking process. To decrease the large proportions of untreated suicidal behaviour, interventions may be needed to expand or reallocate treatment resources, especially in countries with lower access to treatment. Acknowledging that it may not be feasible to provide treatment to everyone who needs it in every country, a more efficient strategy - perhaps implemented in tandem with increased treatment resources would be to target the barriers that are preventing people from receiving available care. Toward this end, our findings suggest that these barriers most often are not structural, financial or stigma-related, but instead concern attitudes that people hold toward seeking treatment for suicidal behaviours.

Ronny Bruffaerts, PhD, Koen Demyttenaere, MD, PhD, Universitair Psychiatrisch Centrum - Katholieke Universiteit Leuven (UPC-KUL), University Hospitals Gasthuisberg, Leuven, Belgium; Irving Hwang, MA, Wai-Tat Chiu, MA, Nancy Sampson, Ronald C. Kessler, PhD, Department of Health Care Policy, Harvard Medical School, Boston, Massachusetts, USA; Jordi Alonso, MD, MPH, PhD, Health Services Research Unit, Institut Municipal d'Investigació Mèdica (IMIM-Hospital del Mar); CIBER en Epidemiología y Salud Pública, Barcelona, Spain; Guilherme Borges, MSc, DrSc, Department of Epidemiological Research, Division of Epidemiological and Psychosocial Research, National Institute of Psychiatry (Mexico) and Metropolitan Autonomous University, Mexico City, Mexico; Giovanni de Girolamo, MD, IRCCS Centro S. Giovanni di Dio Fatebenefratelli, Brescia, Italy; Ron de Graaf, PhD, MSC, Netherlands Institute of Mental Health and Addiction, Utrecht, The Netherlands; Silvia Florescu, MD, PhD, Public Health Research and Evidence Based Medicine Department, National School of Public Health and Health Services Management, Bucharest, Romania; Oye Gureje, MD, PhD, FRCPsych, University College Hospital, Ibadan, Nigeria; Chiyi Hu, MD, MPH, Shenzhen Institute of Mental Health and Shenzhen Kangning Hospital, Shenzhen, China; Elie G. Karam, MD, St George Hospital University Medical Center, Balamand University, Faculty of Medicine, Institute for Development, Research, Advocacy and Applied Care, Medical Institute for Neuropsychological Disorders, Beirut, Lebanon; Norito Kawakami, MD, Department of Mental Health, University of Tokyo Graduate School of Medicine, Tokyo, Japan; Stanislav Kostyuchenko, MD, Ukrainian Psychiatric Association, Kiev, Ukraine; Stanislav Kostyuchenko, MD, Ukrainian Psychiatric Association, Klev, Ukraine;
Viviane Kovess-Masfety, MD, PhD, EA 4069 Université Paris Descartes and EHESP School for Public Health Department of Epidemiology, Paris, France; Sing Lee, MB BS, FRCPsych, Chinese University of Hong Kong, Prince of Wales Hospital, Shatin, Hong Kong, China; Daphna Levinson, PhD, Research and Planning, Mental Health Services Ministry of Health, Jerusalem, Israel; Herber Matschinger, PhD, Clinic of Psychiatry, University of Leipzig, Leipzig, Germany; Jose Posada-Villa, MD, Javeriana University, Centro Medico de la Sabana, Bogota, Colombia; Rajesh Sagar MD, Department of Psychiatry, All India Institute of Medical Sciences, Delhi, India; Kate M. Scott, PhD, Department of Psychological Medicine, Wellington School of Medicine and Health Sciences, Otago, New Zealand; Dan J. Stein, MD, PhD, Department of Psychiatry, University of Cape Town, Cape Town, South Africa; Toma Tomov, MA, PhD, New Bulgarian University, Institute for Human Relations, Sofia, Bulgaria; Maria Carmen Viana, MD, PhD, Section of Psychiatric Epidemiology, Institute of Psychiatry, School of Medicine, University of São Paulo, São Paulo SP, Brazil; Matthew K. Nock, PhD, Department of Psychology, Harvard University, Cambridge, Massachusetts, USA

Correspondence: Dr Ronny Bruffaerts, Universitair Psychiatrisch Centrum Katholieke Universiteit Leuven (UPC-KUL), University Hospitals Gasthuisberg, Leuven, Belgium. Email: ronny.bruffaerts@med.kuleuven.be

First received 28 Jun 2010, final revision 15 Sep 2010, accepted 29 Sep 2010

\section{Funding}

The World Health Organization World Mental Health (WMH) Survey Initiative is supported by the US National Institute of Mental Health (NIMH: R01-MH070884 and MH077883), the John $D$ and Catherine T. MacArthur Foundation, the Pfizer Foundation, the US Public Health Service (R13-MH066849, R01-MH069864 and R01-DA016558), the Fogarty International Center (FIRCA R03-TW006481), the Pan American Health Organization, Eli Lilly \& Co., Ortho-McNeil Pharmaceutical, GlaxoSmithKline and Bristol-Myers Squibb. The work of L.D. was funded by an Australian National Health and Medical Research Council Senior Research Fellowship. The São Paulo Megacity Mental Health Survey is supported by the State of São Paulo Research Foundation (FAPESP Thematic Project Grant 03/00204-3). The Bulgarian Epidemiological Study of common mental disorders is supported by the Ministry of Health and the National Centre for Public Health Protection. The Chinese World Ministry of Health and the National Centre for Public Health Protection. The Chinese World
Mental Health Survey Initiative is supported by the Pfizer Foundation. The Shenzhen Mental Health Survey is supported by the Shenzhen Bureau of Health and the Shenzhen Bureau of Science, Technology and Information. The Colombian National Study of Mental Health is supported by the Ministry of Social Protection. The European Study of the Epidemiology of Mental Disorders (ESEMeD) is funded by the European Commission (contracts QLG51999-01042, SANCO 2004123), the Piedmont Region (Italy), Fondo de Investigación Sanitaria, Instituto de Salud Carlos III, Spain (FIS 00/0028), Ministerio de Ciencia y Tecnología, Spain (SAF 2000-158-CE), Departament de Salut, Generalitat de Catalunya, Spain, Instituto de Salud Carlos III (CIBER CB06/02/0046, RETICS RD06/0011 REM-TAP) 
and other local agencies and by an unrestricted educational grant from GlaxoSmithKline The World Mental Health India study was funded by WHO (India) and helped by Dr R. Chandrasekaran, Jawaharlal Institute of Postgraduate Medical Education and Research. Implementation of the Iraq Mental Health Survey (IMHS) and data entry were carried out by the staff of the Iraqi Ministry of Health and Ministry of Planning with direct support from the Iraqi IMHS team with funding from both the Japanese and European Funds through the Iraqi IMHS team with funding from both the Japanese and European Funds through United Nations Development Group Iraq Trust Fund. The Israel National Health Survey is
funded by the Ministry of Health with support from the Israel National Institute for Health funded by the Ministry of Health with support from the Israel National Institute for Health World Mental Health Japan Survey is supported by the Grant for Research on Psychiatric and Neurological Diseases and Mental Health (H13-SHOGAL-023, H14-TOKUBETSU-026, H16-KOKORO-013) from the Japan Ministry of Health, Labour and Welfare. The Lebanese (LEBANON) is supported by the Lebanese Ministry of Public Health, the WHO (Lebanon), Fogarty International, anonymous private donations to the Institute for Development, Research, Advocacy and Applied Care, Lebanon, and unrestricted grants from Janssen Cilag, Eli Lilly, GlaxoSmithKline, Roche and Novartis. The Mexican National Comorbidity Survey is supported by the National Institute of Psychiatry Ramon de la Fuente (INPRFMDIES 4280) and by the National Council on Science and Technology (CONACyT-630544-H), with supplemental support from the Pan American reath Organization. Te Rau Hine supported by the New Zealand Ministry of Health, Alcohol Advisory Council and Health Research Council. The Nigerian Survey of Mental Health and Wellbeing is supported by the WHO (Geneva), WHO (Nigeria) and the Federal Ministry of Health, Abuja, Nigeria. The Romania WMH study projects 'Policies in Mental Health Area' and 'National Study regarding Mental Health and Services Use' were carried out by National School of Public Health and Health Services Management (former National Institute for Research and Development in (Crom Metro Media Transilvania, the Statistics - National Centre for Training in StatisticS, Cheyenne Services SRL, Statistic Netherlands and were funded by the Ministry of Public Health (formerly Ministry of Health) with supplemental support from Eli Lilly Romania SRL. The South Africa Stress and Health Study is supported by the US National Institute of Mental Health (R01-MH059575) and the National Institute of Drug Abuse with supplemental funding from the South African Department of Health and the University of Michigan. The Ukraine Comorbid Mental Disorders during Periods of Social Disruption study is funded by NIMH (R01-MH61905). The US National Comorbidity Survey Replication is supported by NIMH (U01-MH60220) with supplemental support from the National Institute of Drug Abuse, the Substance Abuse supplemental support from the National Institute of Drug Abuse, the Substance Abuse
and Mental Health Services Administration, the Robert Wood Johnson Foundation (RWJF Grant 044708) and the John W. Alden Trust. A complete list of all within-country and cross-national WMH publications can be found at http://www.hcp.med.harvard.edu/wmh/.

\section{Acknowledgements}

This report was carried out in conjunction with the World Health Organization World Menta Health (WMH) Survey Initiative. We thank the staff of the WMH Data Collection and Dat Analysis Coordination Centres for assistance with instrumentation, fieldwork and data analysis.

\section{Appendix}

\section{Barriers to treatment assessed in the World Mental Health Surveys}

Low perceived need

The problem went away by itself, and I did not really need help.

\section{Structural barriers}

My health insurance would not cover this type of treatment.

I was concerned about how much money it would cost.

I was unsure about where to go or who to see.

I thought it would take too much time or be inconvenient.

I could not get an appointment.

I had problems with things like transportation, childcare or scheduling that would have made it hard to get to treatment.

\section{Attitudinal barriers}

I thought the problem would get better by itself.

I didn't think treatment would work.

I was concerned about what others might think if they found out I was in treatment.

I wanted to handle the problem on my own.

I was scared about being put into a hospital against my will.

I was not satisfied with available services.

I received treatment before and it did not work.

The problem didn't bother me very much.

\section{References}

1 Hawton K, van Heeringen K. Suicide. Lancet 2009; 373: 1372-81.

2 Nock MK, Borges G, Bromet E, Cha CB, Kessler RC, Lee S. Suicide and suicidal behaviors. Epidemiol Rev 2008; 30: 133-54.

3 Murray CJ, Lopez AD. Evidence-based health policy: lessons from the Global Burden of Disease Study. Science 1996; 274: 740-3.

4 Centers for Disease Control and Prevention. Web-based Injury Statistics Query and Reporting System (WISQARS). CDC, 2010 (http://www.cdc.gov/ injury/wisqars/index.html).

5 World Health Organization. WHO Resource Book on Mental Health, Human Rights, and Legislation. Dare to Care. WHO, 2005.

$6 \mathrm{Hu}$ TW. Financing global mental health services and the role of WHO. J Ment Health Policy Econ 2003; 6: 145-7.

7 Mann JJ, Apter A, Bertolote J, Beautrais A, Currier D, Haas A, et al. Suicide prevention strategies: a systematic review. JAMA 2005; 294: 2064-74.

8 Brown GK, Ten Have T, Henriques GR, Xie SX, Hollander JE, Beck AT. Cognitive therapy for the prevention of suicide attempts: a randomized controlled trial. JAMA 2005; 294: 563-70.

9 Linehan MM, Comtois KA, Murray AM, Brown MZ, Gallop RJ, Heard HL, et al. Two-year randomized controlled trial and follow-up of dialectical behavior therapy vs therapy by experts for suicidal behaviors and borderline personality disorder. Arch Gen Psychiatry 2006; 63: 757-66.

10 Rhodes $A E$, Bethell J, Bondy SJ. Suicidality, depression, and mental health service use in Canada. Can J Psychiatry 2006; 51: 35-41.

11 Wang PS, Aguilar-Gaxiola S, Alonso J, Angermeyer MC, Borges G, Bromet EJ, et al. Use of mental health services for anxiety, mood, and substance disorders in 17 countries in the WHO world mental health surveys. Lancet 2007: 370: 841-50.

12 Borges G, Nock MK, Haro JM, Hwang I, Sampson NA, Alaso J, et al. Twelve month prevalence of and risk factors for suicide attempts in the WHO World Mental Health Surveys. J Clin Psychiatry, ePub (doi: 10.4088/ JCP.08m04967blu).

13 World Bank. Data and Statistics. World Bank, 2008.

14 Heeringa S, Wells JE, Hubbard F, Mneimneh ZN, Chiu WT, Sampson NA, et al. Sample designs and sampling procedures. In The WHO World Mental Health Surveys: Global Perspectives on the Epidemiology of Mental Disorders (eds RC Kessler, TB Üstün): 14-32. Cambridge University Press, 2008.

15 Pennell BE, Mneimneh ZN, Bowers A, Chardoul S, Wells JE, Viana MC, et al. Implementation of the World Mental Health Surveys. In The WHO World Mental Health Surveys: Global Perspectives on the Epidemiology of Mental Disorders (eds RC Kessler, TB Üstün): 33-57. Cambridge University Press, 2008.

16 Harkness J, Pennell BE, Villar A, Gebler N, Aguilar-Gaxiola S, Bilgen I. Translation procedures and translation assessment in the World Mental Health Survey Initiative. In The WHO World Mental Health Surveys: Global Perspectives on the Epidemiology of Mental Disorders (eds RC Kessler, TB Üstün): 91-113. Cambridge University Press, 2008.

17 Wittchen HU, Robins LN, Cottler LB, Sartorius N, Burke JD, Regier D. Cross cultural feasibility, reliability and sources of variance of the Composite International Diagnostic Interview (CIDI). Br J Psychiatry 1991; 159: 645-53.

18 Kessler RC, Ustun TB. The World Mental Health (WMH) Survey Initiative Version of the World Health Organization (WHO) Composite International Diagnostic Interview (CIDI). Int J Methods Psychiatr Res 2004; 13: 93-121.

19 Wolter KM. Introduction to Variance Estimation. Springer, 1985.

20 Research Triangle Institute. Professional Software for Survey Data Analysis. RTI, 2002 (http://www.rti.org)

21 De Graaf R, Bijl RV, Smit F, Ravelli A, Vollebergh WA. Psychiatric and sociodemographic predictors of attrition in a longitudinal study: The Netherlands Mental Health Survey and Incidence Study (NEMESIS). Am J Epidemiology 2000; 152: 1039-47.

22 Qin P, Nordentoft M. Suicide risk in relation to psychiatric hospitalization: evidence based on longitudinal registers. Arch Gen Psychiatry 2005; 62 : 427-32.

23 Brown GK, Brown LM, Bhar SS, Beck AT. Cognitive therapy for suicidal older adults. In Handbook of Behavioral and Cognitive Therapies With Older Adults (eds D Gallager-Thompson, AN Steffen, LW Thompson): 135-50. Springer, 2008.

24 Bateman A, Fonagy P. Effectiveness of partial hospitalization in the treatment of borderline personality disorder: a randomized controlled trial. Am J Psychiatry 1999; 156: 1563-9.

25 Simon GE, VonKorff M. Recall of psychiatric history in cross-sectional surveys: implications for epidemiologic research. Epidemiol Rev 1995; 17: 221-7. 
26 Petrou S, Murray L, Cooper P, Davidson LL. The accuracy of self-reported healthcare resource utilization in health economic studies. Int J Technol Assess Health Care 2002; 18: 705-10.

27 Demyttenaere K, Bruffaerts R, Posada-Villa J, Gasquet I, Kovess V, Lepine JP et al. Prevalence, severity, and unmet need for treatment of mental disorders in the World Health Organization World Mental Health Surveys. JAMA 2004; 291: 2581-90.

28 Greenfeld B, Hechtman L, Tremblay C. Short-term efficacy of interventions by a youth crisis team. Can J Psychiatry 1995; 40: 320-4.

29 Isaac M, Elias B, Katz LY, Belik SL, Deane FP, Enns MW, et al. Gatekeeper training as a preventative intervention for suicide: a systematic review. Can J Psychiatry 2009; 54: 260-8.

30 Mojtabai R, Olfson M, Mechanic D. Perceived need and help-seeking in adults with mood, anxiety, or substance use disorders. Arch Gen Psychiatry 2002 59: 77-84.

31 Jorm AF. Mental health literacy. Public knowledge and beliefs about mental disorders. Br J Psychiatry 2000; 177: 396-401.

32 Jorm AF, Angermeyer MC, Katschnig $\mathrm{H}$. Public knowledge of and attitudes to mental disorders: a limiting factor in the optimal use of treatment services.
In Unmet Need in Psychiatry (eds G Andrews, S Henderson): 399-413. Cambridge University Press, 2000

33 Cauce AM, Domenech-Rodriguez M, Paradise M, Cochran B, Shea JM Srebnik $D$, et al. Cultural contextual influences in minority mental health seeking: a focus on ethnic minority youth. J Cons Clin Psychol 2002; 70: $44-55$

34 Goldston DB, Molock SD, Whitbeck LB, Murakami JL, Zayas LH, Nagayama Hall GC. Cultural consideration in adolescent suicide prevention and psychosocial treatment. Am Psychol 2008; 63: 14-31.

35 Corrigan P. How stigma interferes with mental health care. Am Psychol 2004; 59: $614-25$.

36 Arboleda-Florez J. Considerations on the stigma of mental illness. Can J Psychiatry 2003; 48: 645-50.

37 Goldsmith SK, Pellmar TC, Kleinman AM, Bunney WE. Reducing Suicide: A National Imperative. Joseph Henry Press, 2002.

38 Kohn R, Saxena S, Levav I, Saraceno B. The treatment gap in mental health care. Bull World Health Org 2004; 82: 858-66. 